\title{
A natureza da concessão rodoviária do Paraná e suas dificuldades
}

\author{
Rejane Karam* \\ Walter Tadabiro Shima*
}

\section{Introdução}

Tradicionalmente o financiamento da infra-estrutura rodoviária no Brasil foi feito através de recursos públicos, oriundos em especial do Tesouro, por meio da criação de fundos.

A criação do Fundo Rodoviário Nacional - FRN em 27/12/1945, através do Decreto-Lei $\mathrm{n}^{\circ}$ 8.463, conhecido como "Lei Joppert", marcou a fase de maior ascensão de investimentos na infra-estrutura rodoviária. Os recursos eram oriundos do Imposto Único Federal sobre Combustíveis e Lubrificantes Líquidos Minerais e sua destinação era dividida inicialmente entre a União (40\%) e Estados (60\%). Posteriormente, os Municípios passaram a receber 12\%, reduzindo a parcela dos Estados para 48\%. Ao Fundo Rodoviário Nacional foram incorporados também os recursos oriundos da Taxa Rodoviária Única - TRU e do Imposto sobre o Transporte Rodoviário de Passageiros e de Cargas - ISTR.

De forma concomitante, a "Lei Joppert" reestruturou o Departamento Nacional de Estradas de Rodagem - DNER (criado em 1937), conferindo-lhe personalidade jurídica própria e dando-lhe autonomia administrativa e financeira. Em contrapartida, os Estados tiveram a incumbência de criar seus próprios órgãos rodoviários, nos moldes aprovados pelo DNER como requisito para o recebimento e aplicação dos recursos do FRN. A "Lei Joppert" possibilitou o desenvolvimento sustentado do sistema rodoviário, com a implantação da matriz de Política Rodoviária Nacional, a qual, além de garantir recursos específicos para o setor, também propiciou a criação de estruturas técnico-administrativas (DNER e DERs), capacitadas para implementar a infra-estrutura rodoviária. A eficiência do sistema DNER/DER que avançava a passos largos pela década de 60, transformou a malha rodoviária em todo o país. Os Departamentos Estaduais de Estradas de Rodagem estruturados com quadros de pessoal especializado e com um parque de equipamentos próprios, cujas importações foram facilitadas pela "Lei Joppert", desempenharam muito bem a tarefa de executar por administração direta as obras e os serviços de ampliação e

\footnotetext{
* Mestre em Desenvolvimento Econômico pelo Programa de Pós-Graduação em Desenvolvimento Econômico da UFPR e Técnica da Secretaria Estadual dos Transportes. Endereço eletrônico: rejanek@pr.gov.br

** Professor do Programa de Pós-Graduação em Desenvolvimento Econômico da UFPR. Endereço eletrônico: waltershima@,ufpr.br
} 
conservação das rodovias sob suas jurisdições. A malha rodoviária nacional, que em 1940 contava com $775 \mathrm{~km}$ de rodovias pavimentadas de um total de $192.000 \mathrm{~km}$, em 1965 evoluiu para $19.000 \mathrm{~km}$ pavimentados de um total de $570.000 \mathrm{~km}$ de rodovias.

Com a crise do petróleo em 1973 o sistema financeiro internacional se retraiu, obrigando o governo militar a recorrer às fontes internas de financiamento, inclusive remanejando verbas orçamentárias, para fechar suas contas e tentar recuperar as fontes de recursos internacionais.

Com o propósito de financiar projetos prioritários em áreas estratégicas, foi criado em 1974, através da lei no 6.093, o Fundo Nacional de Desenvolvimento - FND, ao qual foram sendo gradativamente transferidos, entre outros recursos federais, os que compunham o FRN. Entre 1975 e 1979 chegou-se a transferir para o FND, 50\% dos recursos destinados ao Fundo Rodoviário Nacional. A partir de 1982, em função do decreto-lei no 1.859, 100\% dos recursos do FRN passaram para o FND culminando em 1983 com a extinção do Fundo Rodoviário Nacional.

O desmonte do modelo de financiamento do setor rodoviário foi completado com o processo de desfederalização dos tributos oriundos dos usuários das rodovias, como a estadualização da TRU (transformada em 1985, em Imposto sobre a Propriedade de Veículos Automotores - IPVA), do IULCLG e do IST (transformados pela Constituição de 1988, em Imposto sobre Operações relativas à Circulação de Mercadorias e sobre Prestação de Serviços de Transporte Interestadual e Intermunicipal e de Comunicação - ICMS).

A partir de 1982 o setor rodoviário passou a contar apenas com os recursos oriundos das dotações previstas nos orçamentos anuais. Considerando que os recursos do Tesouro nunca foram suficientes para o desenvolvimento do setor, e tendo sido vedada a vinculação de receita de impostos a órgão, fundo ou despesa, conforme art.167 da Constituição Federal de 1988, a infra-estrutura rodoviária do País passou a carecer de um volume mínimo de investimentos indispensáveis para a manutenção da malha viária existente e para a construção de novas rodovias.

Como uma tentativa de viabilizar mecanismos de financiamento, instituiu-se o selopedágio e a Taxa de Conservação Rodoviária. O selo-pedágio, criado a partir da lei no 7.712 de 22/12/1988, implicava a aquisição de um selo pelos usuários que trafegavam em rodovias federais, que tinha validade de um mês e daria direito de ir e vir quantas vezes fosse necessário. Os recursos eram recolhidos como receita orçamentária da União. Em função de resultados inexpressivos com as receita obtidas, o selo-pedágio foi extinto através da lei $\mathrm{n}^{\circ}$ 
8.075 de 16/08/1990. A Taxa de Conservação Rodoviária, por sua vez, foi criada com a lei no 8.155 de 28/12/1990 e consistia em um valor anual parcelado em quotas, conforme o combustível utilizado e o rendimento médio do veículo. Contudo, essa taxa foi declarada inconstitucional em 1993.

Recentemente, uma nova tentativa de garantir recursos para o setor rodoviário foi implementada com a lei no 10.336 de 19/12/2001 que instituiu a Contribuição de Intervenção no Domínio Econômico - CIDE, incidente sobre a importação e a comercialização de petróleo e seus derivados, gás natural e seus derivados e álcool etílico combustível, cujos recursos arrecadados destinam-se ao financiamento de programas de infra-estrutura de transportes. A distribuição da Contribuição de Intervenção no Domínio Econômico - CIDE obedece aos seguintes critérios: $40 \%$ proporcionalmente à extensão da malha viária federal e estadual pavimentada do Estado, 30\% proporcionalmente ao consumo de combustíveis, $20 \%$ proporcionalmente à população do Estado e 10\% distribuídos entre Estados e Distrito Federal.

Paralelamente às citadas medidas de vinculação de recursos, já a partir de 1982 foi intensificada a busca por recursos complementares, por meio de financiamentos através de bancos de desenvolvimento nacionais e internacionais.

No caso do Paraná, como alternativa para complementar os recursos necessários à ampliação da malha e à conservação e manutenção das rodovias existentes, em 1977 o Governo Estadual assinou o primeiro empréstimo internacional com o Banco Interamericano Desenvolvimento - BID, cujo objeto era a construção de novas rodovias. Na seqüência, seguiram-se mais três empréstimos com o mesmo agente financiador, sendo que o último, em 1993, teve um enfoque específico na recuperação da malha viária. Entretanto, o aporte de recursos próprios às contrapartidas locais dos projetos de financiamento era muito limitado e, com o gradativo comprometimento da capacidade de endividamento verificou-se uma escassez também das fontes de recursos complementares. $\mathrm{O}$ resultado de todo esse processo foi a deterioração do setor rodoviário, sendo a conservação física da malha rodoviária conduzida de forma precária e insuficiente, uma vez que a incerteza na provisão dos recursos necessários impedia também um planejamento adequado. 


\section{As concessões rodoviárias no Brasil}

A crise do Estado brasileiro iniciada nos anos 80, que diminuiu sensivelmente a sua capacidade de investimento, notadamente no setor de infra-estrutura rodoviária, serviu como cenário ideal para a retomada do pensamento neoliberal, assentado na idéia de que o mercado teria autonomia para gerar estabilidade à economia e bem-estar à sociedade sem a necessidade de intervenção do Estado que era visto como inoperante e burocrático.

O sistema rodoviário brasileiro foi quase todo implementado por órgãos públicos e autarquias criadas especificamente para sua administração, e a exemplo do que ocorreu em outros setores da administração pública, o Estado brasileiro acabou por assumir integralmente os encargos pertinentes à execução de obras e serviços públicos na área de transportes, diretamente ou através de empresas públicas ou de empresas de economia mista. Contudo, a partir do final da década de 60 , pressionada por dificuldades financeiras geradas pela crescente necessidade de infra-estrutura do país e influenciada pelos resultados bem sucedidos de nações como a França, a administração pública começou a valer-se da alternativa da cobrança de pedágio dos usuários de rodovias como forma de aumentar o volume de investimentos.

As primeiras experiências nesse sentido, consistiram na construção de obras pelo poder público e posterior cobrança de pedágio dos usuários, também pelo poder público, visando o ressarcimento dos investimentos realizados, a conservação das vias e a complementação de recursos para novos empreendimentos, entre as quais pode-se citar a BR116/ Rio de Janeiro - São Paulo (Rodovia Presidente Dutra); BR-290/RS: Freeway Porto Alegre - Osório; BR-116/RJ: Rio de Janeiro - Teresópolis - Além Paraíba; BR-040: Rio de Janeiro - Petrópolis - Juiz de Fora; BR-101/RJ: Ponte Rio - Niterói (Ponte Presidente Costa e Silva).

A experiência nacional nessa área, até 1994, implicou a concessão de rodovias a entidades estatais sendo que somente no caso da Terceira Ponte de Vitória houve, na fase final do projeto, o envolvimento da iniciativa privada, numa associação com o Poder Público, para viabilizar a conclusão da obra.

Os debates a respeito da implantação de um processo de concessão de rodovias à iniciativa privada no Brasil iniciaram-se em 1993, com a publicação de Editais pelo DNER de cinco trechos rodoviários federais que, por já terem sido objeto de cobrança de pedágio no passado, serviram como um teste do modelo que viria a ser implantado de forma mais ambiciosa no futuro. 
A nível federal, em janeiro de 1993 foi iniciado o Programa de Concessões de Rodovias Federais - PROCOFE, com o objetivo de transferir a exploração comercial de rodovias federais ao setor privado, através de concessões, visando reduzir os encargos da União nesta área. Foram concedidas ao setor privado cinco rodovias da rede rodoviária federal que haviam sido pedagiadas diretamente pelo DNER no passado. Após a concretização desta primeira fase, com a promulgação da lei no 9277, de maio de 1996 (denominada Lei das Delegações) foram formalizados Convênios com os Estados para a delegação de trechos de rodovias federais, com o objetivo de integrar programas estaduais de concessão. A portaria n ${ }^{\circ} 368 / 96$ do Ministério dos Transportes definiu os procedimentos para a delegação de rodovias federais aos estados e a responsabilidade do DNER pela coordenação e fiscalização da execução dos Convênios de Delegação. Entre 1996 e 1998 foram assinados Convênios de Delegação com os estados do Rio Grande do Sul, Paraná, Santa Catarina e Minas Gerais, que promoveram programas de concessões com estruturas diferenciadas.

Atualmente o governo federal está concluindo a nova modelagem de concessões de rodovias, visando um enfoque ao nível de corredores rodoviários dentro de grandes blocos.

Ainda que a Lei de Concessões tivesse consolidado o modelo de alocação do risco de tráfego às concessionárias, os estados adotaram variações à modelagem federal (cujo critério é o menor valor de tarifa) no que diz respeito ao tipo de licitação.

Considerando os investimentos previstos nos editais, foi utilizado para seleção das melhores propostas a que conduzisse ao maior pagamento de ônus da concessão (Rio de Janeiro e São Paulo) e a que alcançasse maior extensão de trechos a serem mantidos (Paraná e Rio Grande do Sul). A maior desvantagem dessas alternativas é não terem por objeto a modicidade das tarifas, apesar de permitirem vantagens em termos de homogeneização da tarifa por quilômetro na malha concedida. Em virtude das dificuldades na implementação de alguns programas estaduais, o Conselho Nacional de Desestatização, através da resolução no 8 de 5 de abril de 2000, recomendou a revisão do Programa de Delegação de Rodovias Federais e autorizou o Ministério dos Transportes a unificar a política de concessões rodoviárias.

Os problemas relacionados com os processos de concessão estaduais estão basicamente concentrados no seu planejamento. Em sua maioria houve excesso de otimismo quanto à capacidade de absorção pelos usuários da cobrança de pedágio. As medidas adotadas pelo Governo Federal demonstram a fragilidade desse procedimento quando não precedido de um arcabouço institucional e regulatório adequado. 
O arcabouço jurídico construído ao longo do tempo consolidou o instituto da concessão de forma a viabilizar sua implementação com o suporte necessário. A fundamentação legal na qual são pautadas as concessões federais e algumas experiências estaduais (como é o caso do Paraná), se resume à Lei de Licitações e à Lei de Concessões, que tratam das respectivas matérias de forma abrangente, deixando descobertos os aspectos jurídicos específicos a cada setor de infra-estrutura no Brasil.

A despeito de alguns estados brasileiros, como São Paulo e Rio Grande do Sul que constituíram um marco regulatório próprio para o setor rodoviário, as experiências a nível nacional demonstram a grande complexidade na administração de processos de concessão de rodovias e um elevado grau de dificuldade nessa tarefa quando não há um arcabouço regulatório adequado.

\section{O Programa de concessões rodoviárias do Estado do Paraná}

Em 1991, muito antes do implantado Programa de Concessão de Rodovias do Paraná, a Secretaria dos Transportes solicitou aos técnicos do órgão informações sobre a viabilidade de implantação de um sistema de pedagiamento nas rodovias paranaenses, na busca de uma fonte alternativa de recursos que financiasse os investimentos no setor rodoviário, através da cobrança de pedágio. Entre as diversas importantes conclusões do estudo, como por exemplo, a de que seria necessário vultosos investimentos iniciais para a recuperação das diversas rodovias a serem pedagiadas e que seria difícil determinar o valor das tarifas de pedágio, apontou-se três maneiras possíveis de se implantar o sistema de pedagiamento no Paraná: (i) por administração direta; (ii) através de companhia mista; e (iii) através de empresa privada. Após o detalhamento e as ponderações das alternativas para o pedagiamento das rodovias paranaenses, a Comissão concluiu que deveria ser implantado um sistema em etapas, a começar pela implantação de cobrança de pedágio administrada pelo governo. $\mathrm{O}$ trabalho sugere que as demais etapas seguissem uma linha evolutiva a partir da experiência adquirida, justificando a escolha da primeira etapa pela dificuldade de gestão de um processo imediatamente administrado pela iniciativa privada ou através de empresa de economia mista. Porém, o estudo não foi levado adiante por razões de natureza política e ideológicas do Governo naquele momento.

Em 1995, num ambiente político totalmente diferente e sem que se tenha informação da existência de um planejamento mais detalhado e sem o devido cuidado em alicerçar o programa que estava por ser desenvolvido em um marco regulatório que garantisse sua 
exeqüibilidade de forma institucional e jurídica firmando contratos com o objetivo de levantar dados que viabilizassem o programa de concessão de rodovias, o Governo Estadual contratou diversos estudos e pesquisas através de empresas de consultoria privadas, entre os quais o Estudo de Viabilidade para implantação do Programa de Concessão de Rodovias do Paraná com apoio dos técnicos do DER/PR que compreendeu os levantamentos relativos á:

- Contagens de Tráfego;

- Avaliação das condições do pavimento das rodovias federais e estaduais baseada no método "Levantamento Visual Contínuo";

- Pesquisa de Opinião Pública;

- Levantamento aerofotogramétrico;

- Projetos Básicos de engenharia dos trechos a serem concedidos

O método adotado para a análise de viabilidade foi o da Taxa Interna de Retorno (TIR) baseado num fluxo de caixa onde as "entradas" foram representadas pela cobrança do pedágio ao longo do período de concessão, e as "saídas" através das obras, serviços e despesas administrativas/tributárias a serem realizados pelas concessionárias, de acordo com as necessidades detectadas nos trabalhos de campo.

Ressalte-se que o tráfego projetado foi minorado através da inserção de dois fatores inibidores/redutores do tráfego esperado, cuja demonstração não consta do citado trabalho: (i) considerou-se uma parcela de usuários que poderiam reduzir o número de viagens em função da cobrança do pedágio (efeito fuga), com base em pesquisa de opinião realizada pelo Instituto Bonilha em agosto de 1995 em 14 trechos rodoviários do Estado; (ii) a migração de parte do tráfego que utiliza as rodovias a serem concedidas para a Ferroeste, caracterizando uma mudança no modal de transporte. O "Estudo da Receita", que integra o estudo de viabilidade do programa, cita ainda que a evolução do tráfego é de fundamental importância para a determinação do equilíbrio econômico-financeiro do negócio. Contudo, na seqüência alega que "os estudos de tráfego para esse tipo de trabalho servem como balizadores do potencial de receita e sua variação, por trecho de concessão, não precisando, necessariamente, ser muito detalhados, uma vez que a responsabilidade sobre a projeção caberá à futura Concessionária, que assumirá, contratualmente o 'risco do tráfego"'.

Estas considerações da consultora contratada, avalizadas pela equipe de governo responsável pela implantação do programa tornar-se-iam, na seqüência, um dos principais pontos de discussão, considerando que a determinação do tráfego é um dos componentes para a definição da tarifa básica e que o seu comportamento poderá tanto apresentar redução 
quanto acréscimo, cabendo ao Estado não somente uma análise detalhada do tráfego atual e futuro, como o acompanhamento dessa evolução para posteriores ajustes.

Por outro lado, as despesas consideradas ao longo da concessão foram majoradas, principalmente os investimentos iniciais, representadas pelas intervenções para recuperação emergencial e os melhoramentos que teriam por objetivo a operação das vias. Como justificativa para tais incrementos o Estudo alega que "o mercado de serviços rodoviários do Estado do Paraná irá viver um período de grande demanda, já que as expressivas quantidades previstas nos editais deverão ser aplicadas de forma concentrada em um período curto (6 meses)".

O modelo de operação e conservação previu a implantação de serviços de assistência aos usuários (durante 24 horas por dia) envolvendo atendimento médico, socorro mecânico e telefonia; estruturas de gestão, monitoramento de tráfego, conservação rotineira e periódica dos trechos; além da reforma dos postos de pesagem fixos e da Polícia Rodoviária Federal. Durante os 24 anos de concessão foram previstos três ciclos de manutenção, um a cada oito anos. O aumento da capacidade de tráfego e a melhoria das condições de segurança são objetivos das obras de ampliação e melhoria das rodovias e à época do seu lançamento representavam $56 \%$ do volume total de investimentos previstos, número bem maior que os encontrados nas concessões federais e do Estado de São Paulo. A ênfase exagerada nestas despesas, além da repercussão na definição da tarifa básica, aumenta a complexidade do programa em termos de gestão.

Não tendo sido definido um marco regulatório para possibilitar uma gestão mais eficiente, o DER/PR dispõe como instrumento de gestão apenas o contrato de concessão. $\mathrm{O}$ programa de Concessões do Estado do Paraná totaliza atualmente 2.492,52 Km de rodovias, sendo que as principais vias concedidas estão distribuídas em 2.184,23 Km e as rodovias de acesso (oferta) somam 308,29 Km.

A total falta de transparência, desde a concepção do programa, dificulta uma avaliação precisa dos desígnios técnicos e políticos que o norteiam, dando margem a pressupor que interesses particulares se sobrepõem aos de toda a sociedade paranaense.

A partir de abril de 2005, numa nova tentativa de garantir ao programa uma fiscalização adequada, o Estado do Paraná, através do DER/PR, firmou contrato com o Instituto de Tecnologia do Paraná - TECPAR, com a finalidade de assegurar que as obras e serviços de ampliação da capacidade e melhoria, restauração, manutenção e operação das vias, bem como o atendimento aos usuários e aos padrões de qualidade estivessem de acordo com 
os respectivos editais, propostas técnicas, contratos de concessão, termos aditivos e Programas de Exploração do Lote - PER.

Para a realização destas atividades foram criadas equipes técnicas: (i) de apoio central, atuando em conjunto com o DER/PR com a atribuição de verificar a adequação da metodologia de avaliação da rentabilidade financeira do Programa de Concessão de acordo com as normas técnicas do DER/PR e com as normas de contabilidade pública e privada, além de dar suporte geral no controle da execução de obras e serviços de acordo com os planos de investimentos previstos nos contratos de concessão, planos de trabalho, programas de gestão ambiental e aspectos de segurança e atendimento ao usuário de todos os lotes; (ii) de apoio local, atuando em conjunto com as Superintendências Regionais do DER/PR, com a responsabilidade geral de verificar as atividades das concessionárias, de acordo com as exigências estabelecidas nos contratos de concessão, avaliando a conformidade dos estudos, projetos de engenharia e respectivas alterações, das medições das obras e serviços executados, do cronograma de implantação das obras e serviços previstos no PER e nas alterações aprovadas, aferindo ainda a conformidade dos "as built" das intervenções executadas nos lotes, verificando as equipes, instalações e equipamentos das concessionárias com relação à adequação e suficiência para prover a necessária qualidade dos serviços de acordo com as Normas e Especificações. As equipes de apoio local são responsáveis ainda por avaliar o atendimento aos usuários, incluindo a disponibilização dos Livros de Reclamações e Sugestões.

Visando ainda o desenvolvimento institucional e técnico do DER/PR, o contrato prevê a análise crítica dos procedimentos de supervisão e fiscalização, sob a ótica das ferramentas, inclusive de informática, passíveis de utilização nos processos, para inovação e otimização dos resultados quanto à eficiência e eficácia nas vias concedidas, através da avaliação dos procedimentos atuais e proposição de novos procedimentos, incluindo a capacitação especializada para atender às necessidades técnicas oriundas dos novos procedimentos de avaliação de conformidades, dos processos inovativos de gestão a serem implementados e dos resultados das pesquisas e desenvolvimento. 


\section{Críticas e Conclusões}

O planejamento e a implantação do Programa de Concessão de Rodovias foi conduzido de forma autônoma e independente desprezando aspectos importantes dos trabalhos existentes. A despeito de não ter causado nenhuma repercussão ou interferência no processo de concessão implantado, a existência do estudo sobre pedagiamento evidencia o caráter impositivo do Programa de Concessões aos técnicos rodoviários, que não tiveram oportunidade de manifestar qualquer sugestão, nem tampouco se preparar para o novo modelo de atuação do Estado que estava se desenhando. A forma apressada com que foi planejado e implementado o processo de concessão contrasta com a proposição de criação de um ambiente regulatório adequado que permitisse a exeqüibilidade do programa e ainda, reflete erros estruturais e de decisão que culminam atualmente em conflitos intermináveis entre os agentes envolvidos.

Um dos erros estruturais é, por exemplo, a utilização de dados pouco detalhados para a constituição da tarifa básica. Outro erro, este de decisão, foi a escolha do tipo de licitação, abrindo mão do modelo de menor tarifa. O usuário, que é o agente financiador de todo o processo (através do pagamento do pedágio), é negligenciado ao longo do processo, seja pela adoção de um modelo licitatório que não estimula a menor tarifa, seja pelos diversos conflitos entre Estado e Concessionárias que comprometem os investimentos em rodovias, ou ainda pela falta de transparência de todo o processo que aumenta o descrédito em relação ao seu sucesso.

O programa paranaense foi extremamente falho na consideração da figura do usuário, cujas precárias condições de avaliar sua real importância no sucesso ou insucesso das concessões, manifestou-se de forma bastante isolada e sempre contrária ao pedagiamento (greve de caminhoneiros em 1999, manifestações diversas das entidades representativas de transportadores de cargas, cooperativas agrícolas, etc.) com pouca ou nenhuma repercussão para a continuidade do processo até o momento, mas cujo potencial em termos de organização, jamais deve ser desprezado.

Todavia, apesar das limitações do usuário, quanto maior a transparência do processo, maior a facilidade de sua fiscalização pelo próprio usuário. Em 2002, novamente foram celebrados Termos Aditivos aos Contratos de Concessão, por conta da incorporação ao programa, de novos trechos a serem explorados. Assim como em 2000, essa alteração no escopo do programa, com a finalidade de promover o reequilíbrio dos contratos, resultou em diminuição dos investimentos previstos, representada pelo cancelamento e/ou postergação de 
obras de melhoria e ampliação de capacidade das vias. Para os usuários ficou apenas a notícia de redução tarifária.

Neste contexto, sem a existência de uma estrutura regulatória que minimamente possa garantir seu êxito, o processo de concessão fica à mercê dos aspectos legais acordados através do contrato de concessão, cabendo ao DER/PR apenas a fiscalização das ações das concessionárias, sendo que, com inclusão do TECPAR no processo de fiscalização, observouse uma melhora significativa quanto ao conhecimento e análise do conteúdo dos instrumentos de regulação disponíveis, desde o edital até o contrato de concessão, passando pelo Programa de Exploração do Lote que, além de permitir um maior equilíbrio frente a assimetria de informações entre o poder público e as concessionárias, gera a possibilidade de aferição, com um embasamento técnico mais aprimorado e uma estrutura logística mais adequada, das obras e serviços executados pelas empresas. Contudo, as amarrações contratuais e os posteriores termos aditivos, impedem que sejam feitos os necessários ajustes estruturais ao processo, restando apenas fazer cumprir o que já foi estabelecido.

Por definição a estrutura de concessão no Paraná nasceu capturada, o que condena esse processo a permanecer refém de confrontos entre Estado e Concessionárias. A captura do processo pode ser vista, à luz das teorias econômicas, sob dois aspectos: o Estado assumindo a responsabilidade por dados inconsistentes que afetariam o programa permanentemente, atuando em favor de grupos de interesse mais bem organizados e sancionando passivamente os interesses privados em detrimento do bem-estar social. A partir do momento em que o Estado aceita como base de sustentação técnica para a implementação de todo o processo de concessão paranaense, a vigorar por 24 anos, com um alto grau de complexidade e sofisticação, um estudo de viabilidade inconsistente, fundamentado em premissas não confirmadas, certamente estará comprometida a eficiência econômica do processo. Por outro lado a escolha do julgamento da licitação pela maior oferta de trechos de acesso em detrimento da opção pela menor tarifa propicia a elevação dos custos que repercutem no equilíbrio econômico-financeiro, onerando ainda mais o usuário. Esta modalidade, apesar do seu amparo legal, recebeu críticas até do Tribunal de Contas da União e culminou na determinação pela utilização do critério de menor valor da tarifa de pedágio no julgamento das propostas de licitação para concessão de novos trechos federais.

O foco central de todo o problema acerca do processo de concessão do Paraná está na incapacidade de pensar o processo inicial numa perspectiva de independência e conseqüentemente, em defesa do interesse público. Uma tentativa de minorar os impasses 
surgidos somente pode ser pensada a partir do consenso das partes envolvidas: Estado e Concessionárias, em discutir amplamente sobre os termos do contrato e sobre a necessidade de uma estrutura regulatória independente. Fora disso, assimetrias tendem a se perpetuar e o usuário permanecer refém de um complexo e nebuloso jogo de interesses. A incerteza que cerca o processo, como se sabe, gera instabilidade na dinâmica dos investimentos e seus efeitos multiplicadores. Nesse sentido, apenas par citar, do ponto de vista da teoria da regulação econômica, o Programa do Paraná abrange diversos problemas, tais como, seleção adversa/risco moral (em que o concessionário tem mais informações endógenas e exógenas que o concedente), efeito Averch-Johnson (há super-investimento em capital de forma a aumentar a sua remuneração) e, conseqüentemente, captura.

Para finalizar, é importante salientar que a concessão de rodovias à iniciativa privada é um instrumento complementar, não resolve o problema de carência financeira por que passa o setor rodoviário. O Estado do Paraná, tem uma malha de aproximadamente 10.000 Km de rodovias pavimentadas sob a responsabilidade do poder público que, por sua vez, dá mostras de ainda não ter se estruturado institucional, jurídica e tecnicamente para absorver também a função de gestor do sistema.

Num enfoque mais amplo, a prática da função pública no setor rodoviário brasileiro não foge às experiências vividas pelo Estado do Paraná. A partir do esgotamento do modelo de desenvolvimento do "Estado-Empreendedor" o cenário de mudanças em que se insere o setor rodoviário passa a demandar a figura do "Estado-Gestor", que garanta a eficiência econômica sem prescindir da satisfação do usuário. Esta é ainda uma etapa a ser vencida numa situação em que o Estado é refém dos contratos sem que a estrutura de governança vigente permita o rompimento dessa situação capturada, que está longe da defesa do interesse público. Em outros termos, os embates jurídicos atuais entre Governo e concessionários não têm resultado em mudanças alguma no programa. Portanto, a solução poderia estar mais numa busca de cooperação do que disputa política/legal. 